Document downloaded from:

http://hdl.handle.net/10251/104125

This paper must be cited as:

Olmeda, P.; Martín, J.; García Martínez, A.; Villalta-Lara, D.; Warey, A.; Doménech Llopis, V. (2017). A Combination of Swirl Ratio and Injection Strategy to Increase Engine Efficiency. SAE International Journal of Engines. 10(3):1-13. doi:10.4271/2017-01-0722

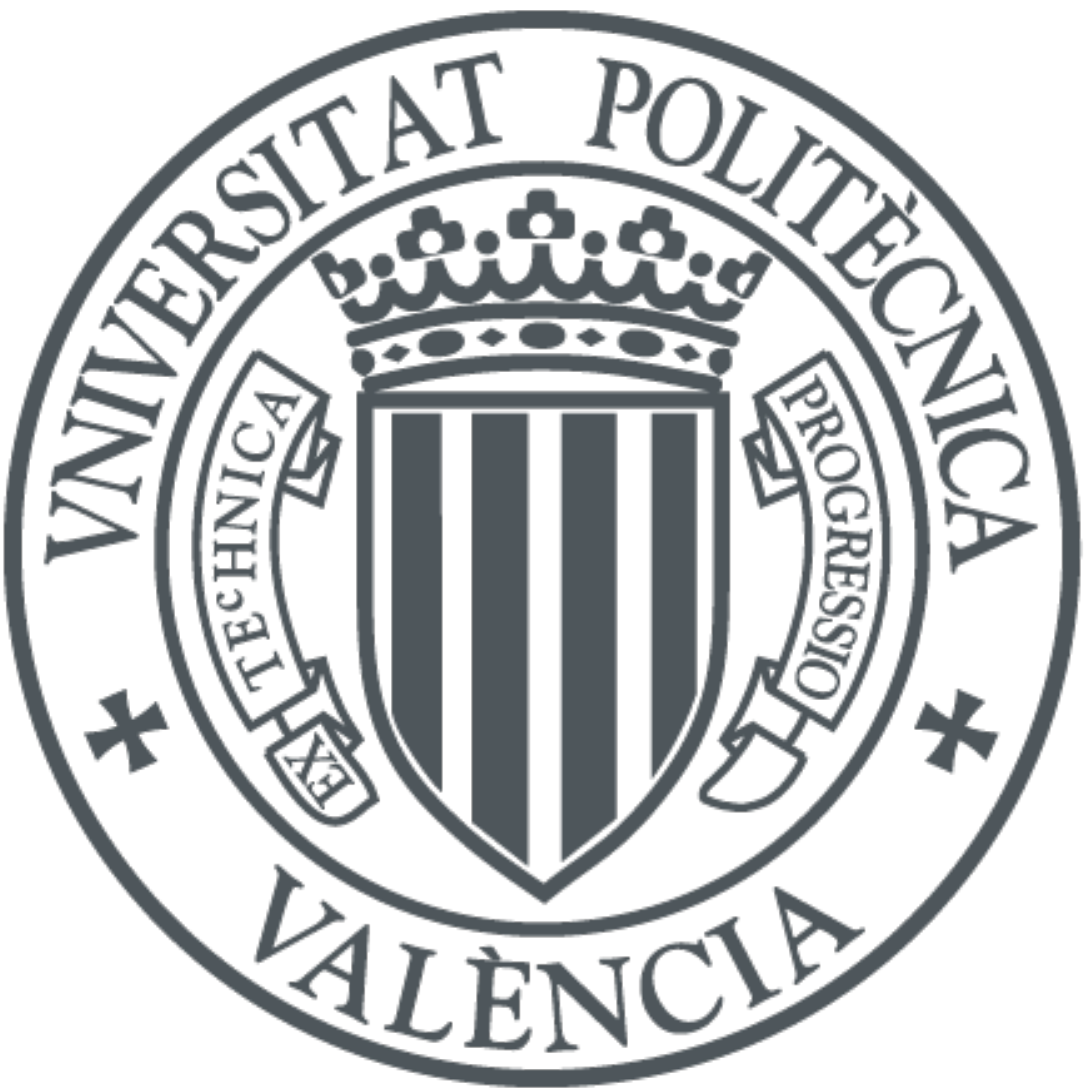

The final publication is available at

http://doi.org/10.4271/2017-01-0722

Copyright SAE International

Additional Information 


\title{
A Combination of Swirl Ratio and Injection Strategy to Increase Engine Efficiency
}

\author{
Author, co-author (Do NOT enter this information. It will be pulled from participant tab in \\ MyTechZone) \\ Affiliation (Do NOT enter this information. It will be pulled from participant tab in MyTechZone)
}

\begin{abstract}
Growing awareness about $\mathrm{CO}_{2}$ emissions and their environmental implications are leading to an increase in the importance of thermal efficiency as criteria to design internal combustion engines (ICE). Heat transfer to the combustion chamber walls contributes to a decrease in the indicated efficiency. A strategy explored in this study to mitigate this efficiency loss is to promote low swirl conditions in the combustion chamber by using low swirl ratios. A decrease in swirl ratio leads to a reduction in heat transfer, but unfortunately, it can also lead to worsening of combustion development and a decrease in the gross indicated efficiency. Moreover, pumping work plays also an important role due to the effect of reduced intake restriction to generate the swirl motion. Current research evaluates the effect of a dedicated injection strategy to enhance combustion process when low swirl is used. For this purpose, a combination of theoretical (OD and 1D models) and experimental tools were used. In particular, experiments were conducted in a single-cylinder directinjection light-duty diesel engine. The analysis also included theoretical calculations to estimate pumping losses. Results show that an increase in swirl ratio leads to an increase in the gross indicated efficiency (balancing heat transfer losses and combustion improvement) but the higher pumping losses negate this positive benefit. In the lowest swirl ratio case, a suitable injection strategy based on multiple injections, together with an increase in the injection pressure, can provide similar gross indicated efficiency as high swirl ratio case while avoiding high pumping losses.
\end{abstract}

\section{Introduction}

Reduction of GHG emissions has become a major concern for the researchers and manufacturers on the automotive industry [1]. $\mathrm{CO}_{2}$ emissions, as the main contributor to greenhouse effect, can be mitigated by diminishing fuel consumption. Thus, currently, different strategies are proposed to get this goal; thermal management improvement [2,3], indicated cycle optimization [4,5], in-cylinder heat transfer (HT) reduction $[6,7,8]$, engine friction and auxiliaries losses reduction $[9,10]$ or new combustion modes $[11,12,13]$ among others. In the present work, the research effort has been focused on obtaining an engine setting combination, which leads to a heat transfer reduction with a combustion process improvement and therefore a better engine thermal efficiency.

In this framework, it is well-known that heat transfer to the combustion chamber walls contributes to decrease the indicated efficiency. One of the most investigated strategies of in-cylinder gas flow affecting heat transfer is swirl ratio variation. In this sense, it has been showed in the literature [14] that to promote low swirl conditions in the combustion chamber by using low or negligible swirl ratios mitigates the indicated efficiency loss. Indeed, low swirl ratio implies lower gas velocity and hence a decrease in the heat transfer coefficient. [14]. In spite of its benefits, to decrease the in cylinder gas motion also implies an important drawback. A weak air motion in the chamber worsens the air-fuel mixing process and promotes slower burning rates [15]. Therefore, low swirl conducts to a contradictory trade-off scenario where it benefits the indicated efficiency by means of a decrease in HT and worsens it since a poor combustion process is developed. In addition, as it is well known [16], the injection pattern governs the combustion process. Higher injection pressures produce an increase in the total air entrained into the fuel, which results in an improvement in the mixing process. A higher momentum of the spray due to an increase in injection pressure produces an increase in the movement of in-cylinder air. In the same way, post injection is demonstrated as a key strategy to influence mixing controlled combustion enhancing fuel oxidation and reducing soot emissions by adding extra momentum flux during this period [17].

In addition, it is necessary to mention that swirl variation has not only impact on indicated efficiency but also on brake efficiency through pumping work. Normally, a throttle plate upstream of the ports provides variable swirl [18]. Thus, when this plate is closed or partially closed, throttles the airflow modifying the flow streams high swirl level is obtained, by contrast when the plate is fully opened the lowest swirl ratio is achieved. This plate has a considerable impact on the air management process since it produces a drop pressure in the port if high swirl level is desired. This fact implies a higher boost pressure to get the same trapped mass at IVC compared with a low swirl case, therefore the turbine section must be reduced to reach the required intake pressure and consequently higher backpressure is also attained.

Considering above explanations, low swirl implies a trade-off between some important advantages (improvement on heat transfer and pumping work) and combustion process worsening. Thus, the main objective of the current research is to evaluate the effect of a dedicated injection strategy to enhance combustion process when low swirl is used with the aim of getting a suitable combination of low heat transfer and combustion process improvement

For this purpose, a combination of theoretical (0D and 1D models) and experimental tools were used. In particular, some preliminary experiments were performed in a dedicated cold test rig to characterize swirl of a single-cylinder direct-injection light-duty diesel engine. Once this works was made, swirl ratio sweeps were 
conducted in the single-cylinder engine. The engine efficiency analysis also included theoretical calculations to estimate pumping losses.

\section{Experimental Facilities}

\section{Steady cold flow test rig}

A cold flow test rig was used to characterize the flow in the cylinder head. The main objective was to determine experimentally how the swirl coefficient changed when the helical and tangential valves are varied. In figure 1, it is shown both valves together with their corresponding pins to vary their position. Manually actuation of these valves was used. Originally, in the multi-cylinder engine base, the swirl ratio was only modified with a helical valve. The swirl ratio range was enclosed from 1.4 to 3 . For thus, in the single-cylinder engine used in the current study, the tangential valve was added. This air management system modification allows to increase the range in terms of swirl ratio compared to the engine base design, from 0 to 5.2 .

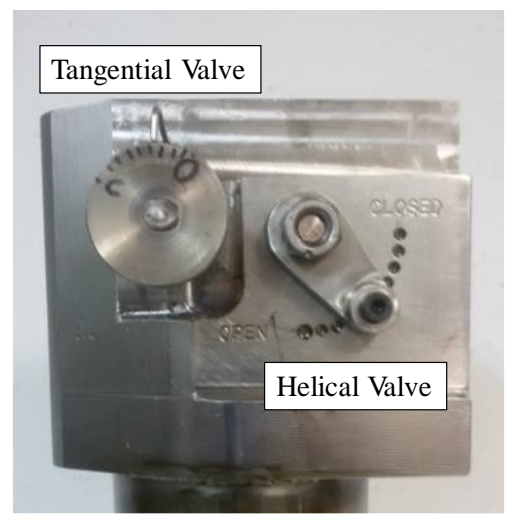

Figure 1. Picture of the helical and tangential dedicated valves to vary the swirl coefficient.

A schematic of the test rig is shown in figure 2. The flow test rig consists of two different tanks, one with 2001 capacity and the other with and 801 , a compressor and an anemometer. It is equipped with a system that can generate pulsating flow by using the main elements of the engine valve timing system. The impulse swirl meter uses a rotating honeycomb type matrix, which is restrained from rotation by a strain-gauged load cell to totally arrest the angular swirl component thereby measuring the resultant angular impulse as a torque. The aspiration tests were performed with this flow rig, for simulating the real flow operating conditions. The raw data were processed using the methodology specified by the manufacturer. The mass flow rate range is $0-0.23 \mathrm{~kg} / \mathrm{s}$, the maximum rated pressure is $1.8 \mathrm{bar}$ and the maximum Mach number that can be measured is 0.18 .

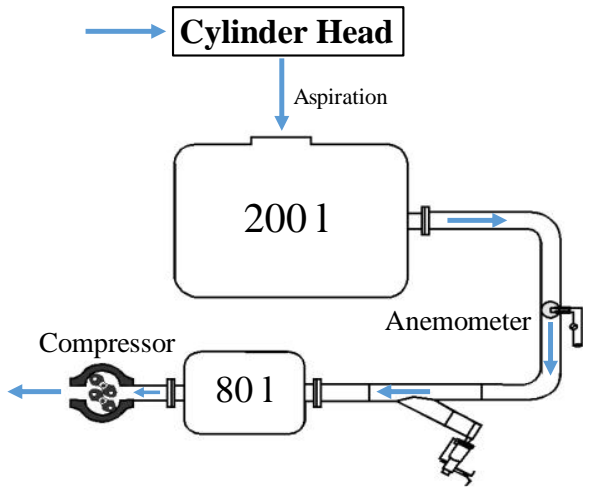

Figure 2. Schematic of the cold flow test rig.

\section{Single-Cylinder Light-Duty Diesel engine}

The study was mainly carried out on a single-cylinder DI Diesel engine. It is derived from a production GM 1.9L Diesel engine equipped with a Common-Rail fuel injection system. The engine has four valves per cylinder, centrally located injector, and a re-entrant type combustion chamber. For the purposes of this study, the engine was equipped with dedicated swirl flaps that can modify the swirl number from 0 up to almost 5.

Engine data and injection system characteristics are depicted in table 1. This engine was set up to meet EURO IV emissions regulations.

Table 1. Engine and injection system specifications

\begin{tabular}{|l|l|}
\hline Engine Type & $\begin{array}{l}\text { DI, 1-cylinder, 4- } \\
\text { stroke }\end{array}$ \\
\hline Displaced volume $\left[\mathrm{mm}^{3}\right]$ & 477 \\
\hline Stroke [mm] & 90.4 \\
\hline Bore [mm] & 82 \\
\hline Combustion Chamber & Re-entrant type \\
\hline Compression ratio & $17.1: 1$ \\
\hline Max. Power [kW] & 27.5 @ 4000rpm \\
\hline Max. Torque [Nm/min $\left.{ }^{-1}\right]$ & $80 / 2000-2750$ \\
\hline Injection System & $\begin{array}{l}\text { Bosch Common Rail } \\
\text { solenoid) }\end{array}$ \\
\hline Max. Rail Pressure [bar] & 1600 \\
\hline Nozzle hole diameter [mm] & 0.141 \\
\hline Injector Nozzle Holes & 7 \\
\hline $\begin{array}{l}\text { Hydraulic flow rate [cm } \\
\text { '(30s) at 100 bar] }\end{array}$ & 440 \\
\hline
\end{tabular}

\section{Test cell}

As figure 3 shows, the single-cylinder engine is installed in a fully instrumented test cell, with all the auxiliary facilities required for operation and control. 


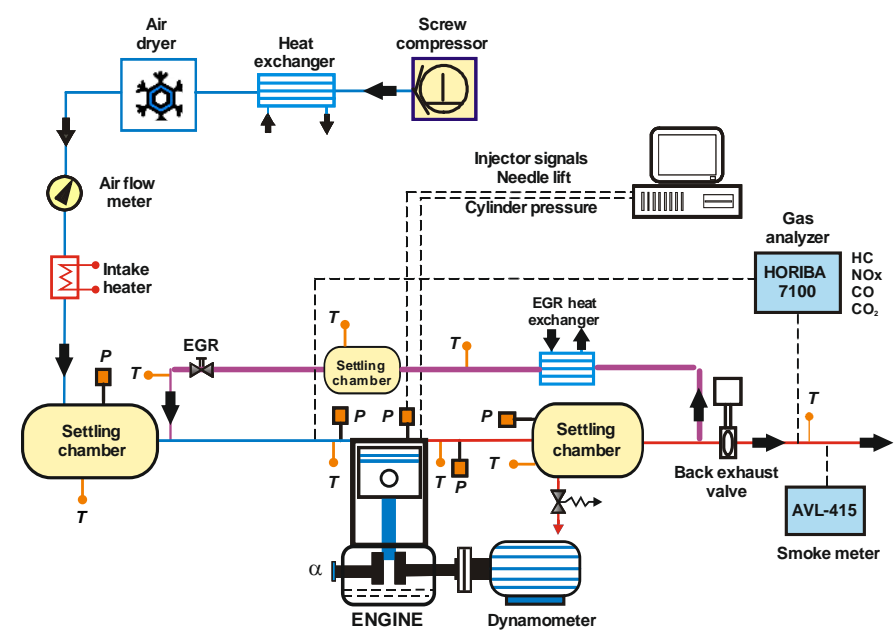

Figure 3. Complete test cell set-up.

To achieve stable intake airflow conditions, an externally driven screw compressor supplied the required boost pressure before passing through an air dryer. The compressor can develop up to 3 bar inlet pressure. The air pressure was adjusted in the intake settling chamber, while intake temperature was controlled in the intake manifold after mixing with EGR. The exhaust backpressure produced by the turbine in the real engine was replicated by means of a valve placed in the exhaust system, controlling the pressure in the exhaust settling chamber. Then, the exact EGR rate was controlled by means of a valve between the EGR settling chamber and the intake pipe, so the required exhaust gas mass flow was introduced into the intake runner depending on the desired EGR rate. The temperature regulation was performed upon the EGR-fresh air mixture using a temperature sensor in the intake manifold. The EGR coolant circuit and the oil coolant circuit were separated from the engine coolant circuit. In this way, the heat rejection to oil, coolant, intercooler and EGR heat exchangers could be analyzed independently. The intercooler was cooled by water unlike the original engine in which an air-water cooler system is used.

The exhaust gases were analyzed with a five gas Horiba MEXA $7100 \mathrm{D}$ analyzer bench. In order to increase the robustness of these measurements, the different pollutant volume fractions were sampled and averaged over a 60 second time period after attaining steady state operation.

Smoke emissions were measured with an AVL 415 variable sampling smoke meter, providing results directly in FSN. The FSN values used in this research are the average of three consecutive measurements at the same operating condition. These measurements were transformed into $\mathrm{mg} / \mathrm{m}^{3}$ by means of the correlation (1) proposed in the user manual of the device:

$$
\left[\mathrm{mg} / \mathrm{m}^{3}\right]=\frac{1}{0.405} \cdot 4.95 \cdot F S N \cdot e^{0.38 \cdot F S N}
$$

The installation also included complete instrumentation to measure different fluid temperatures and mass flows. A combination of thermocouples and resistance temperature detectors (PT100) were selected (taking into account the expected temperature variation) to measure liquid and gas temperatures. The in-cylinder pressure was measured with a Kistler $6125 \mathrm{C} 10$ glow-plug piezoelectric transducer and Kistler 4603B10 charge amplifier. A crank angle increment of $0.5^{\circ}$ was used for the in-cylinder pressure acquisition [19], which was

Page 3 of 14 performed using DRIVVEN [20]. The list of the relevant instrumentation is shown in Table 2.

The mean variables were acquired at a low sample frequency of $100 \mathrm{~Hz}$ using SAMARUC, a CMT-developed test system that collects the signals of different sensors and controls the dynamometer [21].

Table 2. Test cell instrumentation.

\begin{tabular}{|l|l|l|}
\hline Variables Measured & Sensors & Range \\
\hline $\begin{array}{l}\text { Temperature of liquids (coolant, } \\
\text { oil, cooling water at } \\
\text { exchangers...) }\end{array}$ & $\begin{array}{l}\text { Thermoresistors } \\
\text { (PT100) }\end{array}$ & $-30-350{ }^{\circ} \mathrm{C}$ \\
\hline $\begin{array}{l}\text { Temperature of gases (inlet and } \\
\text { exhaust lines, EGR...) }\end{array}$ & K-type Thermocouples & $-200-1250{ }^{\circ} \mathrm{C}$ \\
\hline Fuel mass flow & AVL 7351 & $0-34.72 \mathrm{~g} / \mathrm{s}$ \\
\hline Air mass flow & Sensyflow P & $10-400 \mathrm{~kg} / \mathrm{h}$ \\
\hline Coolant Flow & DN25 Flow meter & $8.8-350 \mathrm{l} / \mathrm{min}$ \\
\hline Torque & Dynamometer & $0-400 \mathrm{Nm}$ \\
\hline In-cylinder pressure & Kistler 6125C10 & $0-300 \mathrm{bar}$. \\
\hline
\end{tabular}

\section{Theoretical tools}

\section{0-D models}

Two different 0-D single-zone thermodynamic models (CALMEC and siCiclo) were used. Main assumptions for both are the same:

- Chamber pressure and temperature are assumed to be spatially uniform. In combustion calculations, both fluid and flame velocities are lower than the speed of sound.

- Three species (air, fuel vapor and stoichiometric combustion products) are considered. The flame is located in the stoichiometric fuel-air ratio region of conventional diesel combustion and thus this hypothesis is assumed [22].

- Ideal gas law is used to calculate mean gas temperature. Perfect gas behavior is assumed.

- A filling and emptying model is used to calculate the trapped mass [23]. A simple filling and emptying model has been used to estimate the residual mass and the shortcircuit mass. When they are known, the trapped mass at IVC has been calculated using next expression.

$$
\mathrm{m}_{\mathrm{IVC}}=\mathrm{m}_{\mathrm{a}}+\mathrm{m}_{\mathrm{EGR}}+\mathrm{m}_{\mathrm{res}}-\mathrm{m}_{\mathrm{sc}}
$$

where $m_{a}$ and mEGR are the air and EGR masses, mres is the residual mass of the previous cycle and $\mathrm{m}_{\mathrm{sc}}$ is the shortcircuit mass.

- Specific heat of the gas depends on both temperature and composition. This assumption is consistent with the second and third hypothesis [24].

- Blow-by model is based on the evolution of the gas in an isentropic nozzle [23]. The instantaneous mass flow of blow-by to the crankcase is estimated by means of the equation of an adiabatic nozzle as:

$$
m_{b b}=c_{b b} A_{r e f} p \sqrt{\frac{x}{R_{C} T}}
$$


where $\mathrm{x}=\frac{2 \gamma}{(\gamma-1)}\left[\left(\frac{\mathrm{p}_{\mathrm{crk}}}{\mathrm{p}}\right)^{\frac{2}{\gamma}}-\left(\frac{\mathrm{p}_{\mathrm{crk}}}{\mathrm{p}}\right)^{\frac{\gamma+1}{\gamma}}\right]$. The discharge coefficient of the nozzle, cbb, was adjusted with experimental measurements so that the cumulative blow-by coincided with the actual flow, $\mathrm{A}_{\text {ref }}$ is the reference section $\left(3.5 \times 10^{-6} \mathrm{D}\right), p_{\text {crk }}$ is the crankcase pressure and $R_{c}$ and $T$ are compression ratio and temperature, respectively.

- Chamber volume deformation is calculated by means of a simple deformation model [25]. The instantaneous volume is obtained as the addition of three terms: the combustion chamber volume, the volume displaced by the piston (depending on crank angle) and the mechanical. deformations produced by the gas pressure and the inertial efforts of the masses with reciprocating motion. A simple deformation model, described in [22], is used to calculate the last term.

- Heat transfer to the chamber walls is calculated with a modified Woschni-like model [26].

$\mathrm{h}=\mathrm{CD}^{-0.2} \mathrm{p}^{0.8} \mathrm{~T}^{-053}\left[\mathrm{C}_{\mathrm{W} 1} \mathrm{c}_{\mathrm{m}}+\mathrm{C}_{\mathrm{W} 2} \mathrm{c}_{\mathrm{u}}+\mathrm{C}_{2} \frac{\mathrm{V}_{\mathrm{d}} \mathrm{T}_{\mathrm{IVC}}}{\mathrm{V}_{\mathrm{IVC}} \mathrm{p}_{\mathrm{IVC}}}\left(\mathrm{p}-\mathrm{p}_{0}\right)\right]^{0.8}$ where $\mathrm{C}$ and $\mathrm{C}_{2}$ are constants whose values are 0.12 and $0.001, c_{m}$ is the mean piston speed, $c_{u}$ is the instantaneous tangential velocity of the gas in the chamber that was adjusted using CFD calculations, $\mathrm{p}_{0}$ is the pressure during motoring conditions assuming a polytrophic evolution, and finally $\mathrm{CW}_{\mathrm{W} 1}$ and $\mathrm{CW}_{\mathrm{W}}$ are constants, whose values are adjusted for each engine by means of a combination of experimental and modelling methodology.

The combustion analysis was performed by means of an in-house tool named CALMEC, which is comprehensively described in [27]. This thermodynamic tool uses the in-cylinder pressure signal as the main input, which is measured from 100 consecutive engine cycles in order to reduce the cycle-to-cycle experimental uncertainties. The raw pressure signal was smoothed by the a low-pass filter and averaged in order to obtained a representative in-cylinder pressure trace, which was used to perform the analysis. Then the first law of thermodynamics was applied between IVC (Intake Valve Close) and EVO (Exhaust Valve Open), considering the combustion chamber as an open system because of blow-by and fuel injection. The main result of the thermodynamic tool used was the rate of heat release (RoHR) along with some representative parameters such as the start of combustion (defined as the crank angle degree in which the cumulated heat release reaches $2 \%$ of the total fuel energy) and the CA50 (defined as the crank angle at 50\% mass burned, among other parameters.

Siciclo [22] is a predictive thermodynamic model, in which the mass and energy conservation equations are solved in order to obtain the instantaneous gas state in the combustion chamber. This tool calculates the in-cylinder pressure trace using the experimental RoHR as main input. The model includes some specific sub-models to reproduce the blow-by leakage, the chamber deformation due to pressure and inertial efforts, the heat transfer to the chamber walls and the fuel injection. This code was used in this research to predict engine performance and fuel consumption and also to obtain boundary conditions.

\section{1-D model}

A 1-D model developed in the GT-Suite commercial software was used to calculate pumping work when the swirl ratio is varied in order to impose them in the single-cylinder tests. The model was adjusted with multi-cylinder engine tests previously measured in [6]. In this sense, instantaneous measured and modeled in-cylinder pressure, intake and exhaust pressures, along with air mass flow measurement were compared to validate the model performance at four different operating points with four different swirl ratio levels. Inputs to the 1-D model were experimental wall temperatures, injection strategy settings and fuel mass, as well as RoHR obtained with CALMEC. Experimental gas temperatures, pressures, and air mass flow were used as targets during model tuning.

\section{Methodology}

\section{Engine operating conditions and testing procedure}

The engine was operated at two different engine loads maintaining constant engine speed at $2000 \mathrm{rpm}$. In particular, low load (5 bar BMEP) and high load (20 bar BMEP) cases were selected to evaluate the potential of combining different injection strategies and swirl ratios to maximize the engine efficiency. In this sense, different injection strategies (SoIs and injection pressure), swirl number, intake and exhaust pressures were tested.

Thus, for each load, two steps were carried out. In a first step, a parametrical swirl variation maintaining CA50 constant. In a second step, the injection pressure, SOE's, Energizing Time's, and number of injections of the lowest pumping work case (low SR condition) were modified to get similar RoHR as the case with the highest Gross Indicated Efficiency, high SR condition (not only CA50 but also CA10, CA25, CA75 and CA90). Thus, the main objective of this second step was to maximize the brake efficiency (indicated efficiency vs pumping work) for each load.

Thus, starting with the first step, to isolate the effects of swirl ratio variation, all engine parameters except the swirl were kept constant. Therefore, tests were performed with the same pressure, temperature and trapped mass at the IVC, as well as the same CA50 and fuel mass. Engine settings for this first step in each load are shown in table 3 . 
Table 3. Engine operating conditions during first step of the methodology

\begin{tabular}{|l|c|c|}
\hline Operation condition & $\begin{array}{c}\text { 2000rpm at 5bar } \\
\text { BMEP }\end{array}$ & $\begin{array}{c}\text { 2000rpm at 20bar } \\
\text { BMEP }\end{array}$ \\
\hline Torque [Nm] & 17 & 59 \\
\hline Load [\%] & 24 & 100 \\
\hline Engine speed [RPM] & 2000 & 2000 \\
\hline Injection pressure [bar] & 650 & 1250 \\
\hline Fuel Flow [mg/str] & 18 & 50 \\
\hline Number of Injections & 3 & 3 \\
\hline SoE [ ${ }^{\circ}$ BTDC] & $19.5 / 9.9 / 0.3$ & $22.6 / 13 / 3.4$ \\
\hline ET [ms] & $0.310 / 0.310 /$ & $0.250 / 0.250 /$ \\
& $0.582-0.590$ & $0.838-0.860$ \\
\hline$T_{\text {in }[\mathrm{K}]}$ & $1.30-1.41$ & $2.23-2.33$ \\
\hline Pin [bar] & 1.56 & 2.78 \\
\hline Pexh [bar] & 0.659 & 1.083 \\
\hline Air Flow [kg/min] & \multicolumn{2}{|c|}{0} \\
\hline EGR [\%] & \multicolumn{2}{|c|}{13} \\
\hline CA50 [ ${ }^{\circ}$ aTDC] & \multicolumn{2}{|c|}{} \\
\hline
\end{tabular}

In addition, the coolant and oil temperatures remained constant in all the tests at $86^{\circ} \mathrm{C}$ and $95^{\circ} \mathrm{C}$ respectively. The minimum swirl ratio was 0 for all the cases, while the maximum level for each point was selected taking into account three limitations: soot limit $(\mathrm{FSN}=3)$, combustion stability (Coefficient of Variance of IMEP lower than $3 \%$ ), to get the maximum achievable level. In particular, the maximum value of FSN was 2.34, while the maximum value of the COV of IMEP was $2 \%$. Both values were obtained at low load with the $\mathrm{SR}=0$. In order to reduce experimental uncertainties five repetitions of each point were measured and the result was averaged, considering as acceptable uncertainties lower than $1 \%$ for the air and fuel mass flow measurements.

Once the swirl ratio impact was quantified in terms of combustion process, a second step was proposed. Thus, a drastic variation of the injection strategy (number of injections, duration of each injection event and injection pressure) was evaluated as figure 4 shows. The objective is to obtain as much similar RoHR (CA10, CA25, CA50, CA75 and CA90) as possible independently on the swirl ratio used and considering as a RoHR reference the one obtained with the SR level that produces the lowest pumping work. The strategy developed in this study is presented in figure 5 .

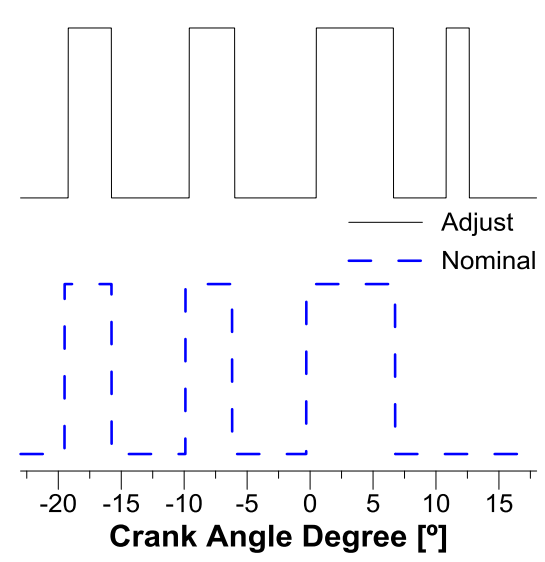

Figure 4. Evolution temporal of Injection strategies for the case $\mathrm{SR}=1.5$ nominal (3 injections) and adjust (4 injections).

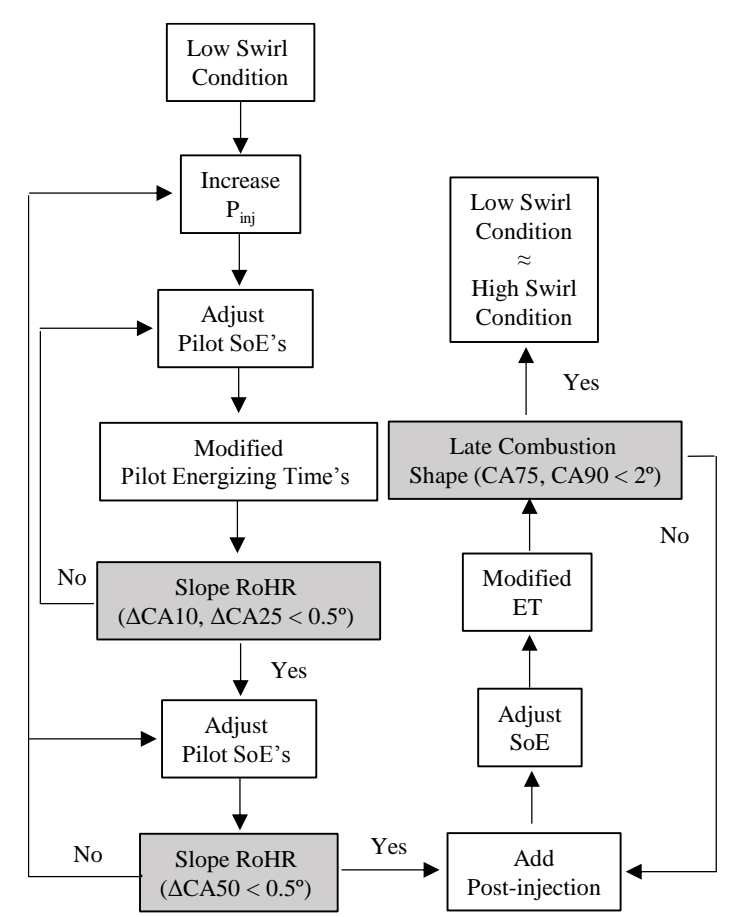

Figure 5. Experimental procedure carried out to similar RoHR using two different swirl ratios.

Thus, to replicate the RoHR obtained with the highest swirl ratio tested using the lowest swirl, different steps are proposed. First, an increase in the injection pressure is promoted in steps of 50 bar. Faster RoHR with higher peak is obtained after this process. In a second step, a Start of Energizing (SOE) Time sweep as well as the Energizing Time (ET) adjustment of the nominal injection strategy is evaluated to get similar RoHR. Finally, a fourth injection (post injection) was added to compensate for the worst mixture formation case of late combustion at low swirl. Engine settings for this second step in each load are shown in table 4. 
Table 4. Engine operating conditions used to replicate the RoHR obtained with the highest swirl ratio $(S R=3)$ using low swirl ratio condition $(S R=1.5)$

\begin{tabular}{|c|c|c|}
\hline Operation condition & $\begin{array}{l}\text { 2000rpm at 5bar } \\
\text { BMEP }\end{array}$ & $\begin{array}{l}\text { 2000rpm at 20rpm } \\
\text { BMEP }\end{array}$ \\
\hline Torque [Nm] & 17 & 59 \\
\hline Load [\%] & 24 & 100 \\
\hline Engine speed [RPM] & 2000 & 2000 \\
\hline $\begin{array}{l}\text { Injection pressure } \\
\text { [bar] }\end{array}$ & 800 & 1350 \\
\hline Swirl Ratio [-] & 1.5 & 1.5 \\
\hline Fuel Flow [mg/str] & 18 & 50 \\
\hline Number of Injections & 4 & 4 \\
\hline SoE $\left[{ }^{\circ} \mathrm{BTDC}\right]$ & $\begin{array}{c}19.2 / 9.6 /-0.5 / \\
-4.7\end{array}$ & $23 / 13.4 / 3.8 /-2.8$ \\
\hline $\mathrm{ET}[\mathrm{ms}]$ & $\begin{array}{c}0.285 / 0.300 / \\
0.510 / 0.150 \\
\end{array}$ & $\begin{array}{c}0.245 / 0.242 / \\
0.710 / 0.215 \\
\end{array}$ \\
\hline $\mathrm{T}_{\mathrm{in}}[\mathrm{K}]$ & \multicolumn{2}{|c|}{318} \\
\hline $\mathrm{P}_{\text {in }}[\mathrm{bar}]$ & 1.304 & 2.228 \\
\hline$P_{\text {exh }}[\mathrm{bar}]$ & 1.56 & 2.783 \\
\hline Air Flow [kg/min] & 0.659 & 1.083 \\
\hline EGR [\%] & \multicolumn{2}{|c|}{0} \\
\hline $\mathrm{CA} 50\left[^{\circ} \mathrm{aTDC}\right]$ & \multicolumn{2}{|c|}{13} \\
\hline
\end{tabular}

Commercially available European diesel fuel was used for this work. Table 5 shows the main characteristics of the fuel used.

Table 5. Fuel properties at 1 atm and $40^{\circ} \mathrm{C}$.

\begin{tabular}{|l|c|}
\hline Fuel & Diesel \\
\hline Cetane Number & 50.8 \\
\hline $\begin{array}{l}\text { Density @313K } \\
\text { [kg/m3] }\end{array}$ & 820 \\
\hline $\begin{array}{l}\text { Distillation @ 65/ 85/ } \\
\text { 95\% [K] }\end{array}$ & $568.3 / 601.4 / 624$ \\
\hline HC Ratio & 6.05 \\
\hline $\begin{array}{l}\text { Weight Molecular } \\
\text { [g/mol] }\end{array}$ & 215.42 \\
\hline $\begin{array}{l}\text { Dynamic Viscosity } \\
\text { @ 313K [cSt] }\end{array}$ & 2.38 \\
\hline
\end{tabular}

\section{Results and discussions}

\section{Swirl valves characterization}

Before starting with engine test campaigns, a dedicated work to characterize swirl valves is performed. In this sense, figure 6 top, shows different swirl ratios measured versus different pin positions for the swirl valve on the tangential port. In the same way, figure 6 bottom, details swirl ratios obtained versus different pin positions for the swirl valve on the helical port.
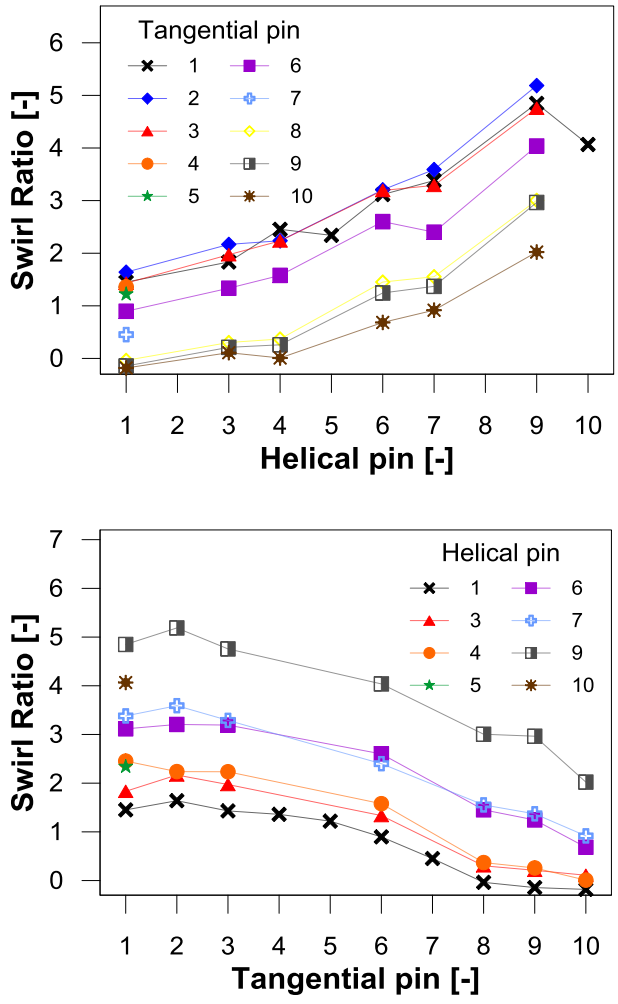

Figure 6. Swirl ratios obtained by different pin positions maintaining constant tangential pin (top) and helical pin (bottom).

Thus, after the experimental characterization of the (SCE) singlecylinder Engine cylinder head it is possible to state that helical valve sweep provides wider SR variation $(1.5-4.8)$ than the production engine: $(1.4-2.9$, previously characterized [7]). With this new system, through the combination of helical and tangential valves, it is possible to sweep a wide range of SR, between low swirl conditions $\mathrm{SR}=0$ up to very high SR level, 5.2.

In addition, the table 6 shows the different tangential and helical pin positions for the swirl sweep measured ( $\mathrm{SR}=0$ to 5) in the SCE.

Table 6. Helical and tangential pin position for each swirl ratio.

\begin{tabular}{|c|c|c|}
\cline { 2 - 3 } \multicolumn{1}{c|}{} & $\begin{array}{c}\text { Helical pin } \\
\text { position }\end{array}$ & $\begin{array}{c}\text { Tangential } \\
\text { pin position }\end{array}$ \\
\hline $\mathbf{S R}=\mathbf{0}$ & 1 & 8 \\
\hline $\mathbf{S R}=\mathbf{1}$ & 1 & 6 \\
\hline $\mathbf{S R}=\mathbf{1 . 5}$ & 1 & 1 \\
\hline $\mathbf{S R}=\mathbf{2}$ & 3 & 3 \\
\hline $\mathbf{S R}=\mathbf{3}$ & 6 & 1 \\
\hline $\mathbf{S R}=\mathbf{4}$ & 8 & 2 \\
\hline $\mathbf{S R}=\mathbf{5}$ & 9 & 2 \\
\hline
\end{tabular}




\section{Low load case: 5 bar BMEP}

\section{Engine efficiency study}

Using RoHR controlling the CA50, a complete swirl sweep was performed at 2000rpm at 5bar BMEP. Figure 7 presents the Gross Indicated Efficiency (GIE) for seven different swirl ratios, ranged from 0 to 5 for the SCE tested. It is also added the GIE for the production Multi Cylinder Engine (MCE) version of the same engine with different swirl flaps. These values were obtained in previous research [28]. Thus, it can be said that the global trend is similar between both engines but with different SR levels. Both profiles present an increase on GIE with the increase of swirl ratio up to a maximum and later a decrease on GIE when the SR is higher than the one the engine is designed for and also the rest of the hardware. In this sense, the maximum benefit for 5 bar bmep is obtained at different SR levels. ( $S R=2$ for the MCE, $S R=3$ for the SCE). It is important to highlight that similar SR implies a different in-cylinder flow field for each engine due to geometrical differences in the intake ports. Thus, local mixing process and therefore combustion are enhanced for the SCE case providing higher GIE than MCE when similar SR is used. Nonetheless, the most relevant fact is the difference in terms of engine efficiency benefit. For the multicylinder engine GIE differences are practically negligible. For the SCE case, an improvement of $1.8 \%$ in GIE is obtained comparing SR $=0$ and $\mathrm{SR}=3$. Since $\mathrm{SR}=3$, the increase in swirl ratio produces a deterioration of the combustion development due to excessive spray interaction [29] and/or a displacement of the combustion process towards the squish region, which implies a worsening in combustion [29].

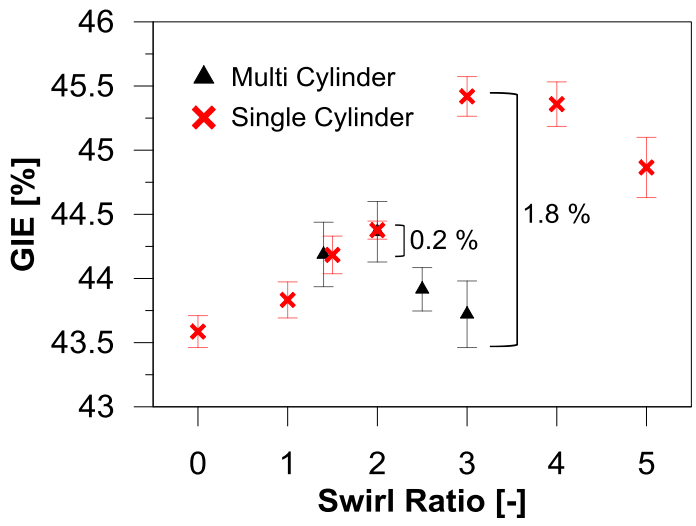

Figure 7. Gross indicated efficiency at different swirl ratios for singlecylinder engine and multi-cylinder engine.

The impact of the SR in the gross indicated efficiency is a balance between combustion process enhancement and heat transfer losses. To show this behavior, figure 8 shows the temporal evolution of the RoHR and the cumulative HR for the 7 different swirl ratios tested. From 0 to 5 in steps of 1 unit and adding the $S R=1.5$.

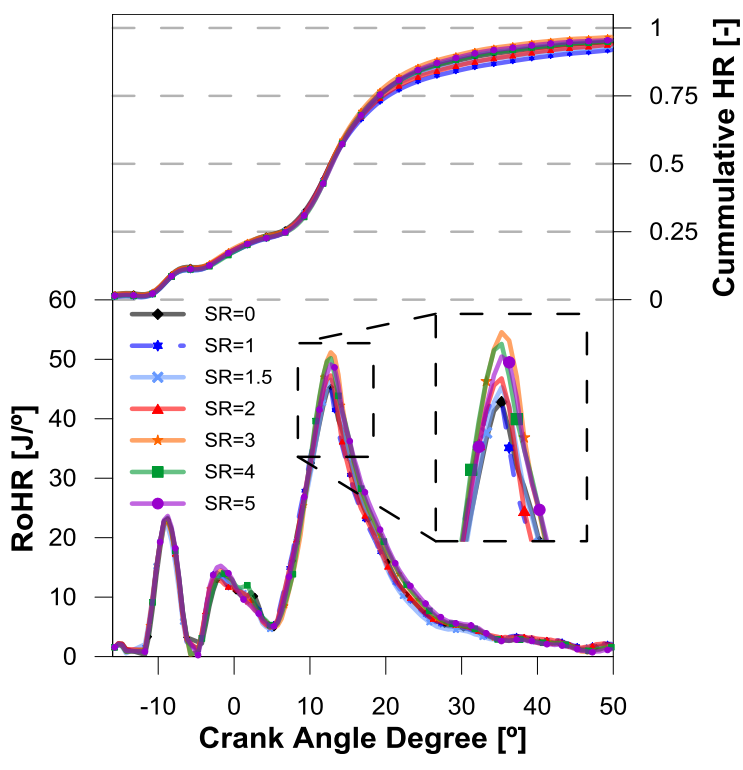

Figure 8. The temporal evolution of the cumulative HR (top) and the RoHR (bottom) for the different swirl ratios tested.

Looking at RoHR profiles for the extreme SR cases, 0 and 5, it is clear to state that, when the SR is increased, there is a higher maximum peak of RoHR (slight discrepancy appears with $\mathrm{SR}=4$ and 5 ). In the same way, there is also a higher energy released during expansion stroke. On the other side, combustion onset is similar between all SR tested as well as the combustion development during the pilot injections burnt. Thus, it could be concluded that, when SR is increased, an enhancement of the mixing process leads to a higher and faster heat release process, which could be beneficial to get higher gross indicated efficiency depending on the heat transfer response. Thus, looking at figure 7 , the GIE increases up to $\mathrm{SR}=3$ and later decreases due to the balance of the two opposite trends, heat transfer increase and combustion enhancement. With the aim of clarifying this contradictory behavior, a short analysis was made with the 0 -D code ( $\mathrm{SiCiclo).} \mathrm{Adiabatic} \mathrm{combustion} \mathrm{was} \mathrm{simulated} \mathrm{to}$ isolate combustion and heat transfer effects. Figure 9 shows the indicated efficiency, the RoHR and heat transfer variation at different swirl ratios. Values for the $1.5 \mathrm{SR}$ case are used as references since this SR presents the lowest pumping work. The values of gross indicated efficiency are the same as shown in the figure 7. GIE variation were calculated subtracting GIE for each SR case and GIE for $\mathrm{SR}=1.5, \Delta \mathrm{GIE}_{\mathrm{SR}}=\mathrm{GIE}_{\mathrm{SR}}-\mathrm{GIE}_{\mathrm{SR}=1.5}$. RoHR term was calculated by means of adiabatic combustion and it was simulated to isolate combustion effect. $\Delta$ RoHR was obtained as the difference between RoHR for each SR cases and RoHR of $\mathrm{SR}=1.5$ case reference, $\Delta \mathrm{RoHR}_{\mathrm{SR}}=\mathrm{RoHR}_{\mathrm{SR}}-\mathrm{RoHR}_{\mathrm{SR}}=1.5$. the global trend was similar between GIE and RoHR. The maximum benefit was obtained at $\mathrm{SR}=3$. Further than $\mathrm{SR}=3$, the increase in swirl ratio worsened the combustion development due to excessive spray interaction. Finally, HT effect represents the heat transfer process. $\Delta \mathrm{HT}$ effect is calculated as: $\Delta \mathrm{HT}_{\mathrm{SR}}=\left(\mathrm{RoHR}_{\mathrm{SR}}-\mathrm{RoHR}_{\mathrm{SR}}=1.5.\right)-\left(\mathrm{GIE}_{\mathrm{SR}}-\mathrm{GIE}_{\mathrm{SR}}=\right.$ 1.5). As it is well known, the drawback of high SR condition is the increase of heat transfer losses to the chamber walls as shown in figure 9 . 


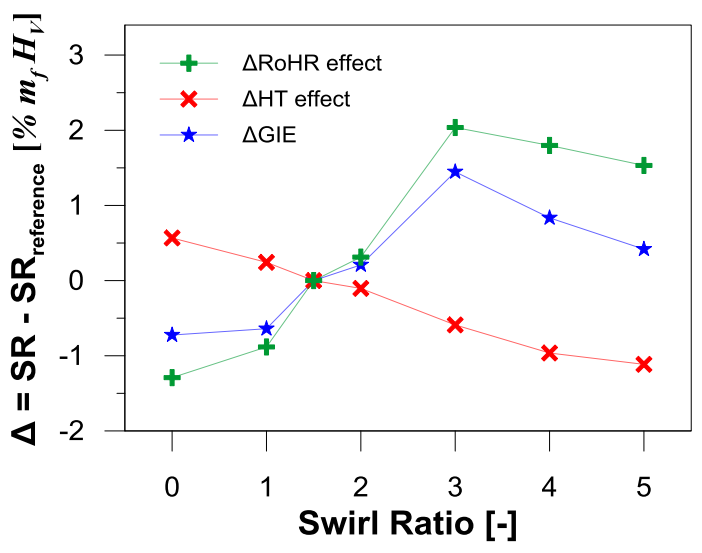

Figure 9. Gross Indicated Efficiency variation vs swirl ratio sweep considering SR = 1.5 as reference case and splitting the RoHR and heat transfer effects ( 5 bar BMEP).

To evaluate SCE pumping work is used 1D modelling. In this sense, the model was adjusted using MCE tests previously measured. Intake and exhaust pressures, along with air mass flow measurement at IVC were adjusted between both different cylinder heads to get similar values when SR valves position are comparable. So, figure 10 shows pumping losses for MCE and SCE versus SR (considering as reference the $\mathrm{SR}=1.5$ case since it is providing the lowest lost level).

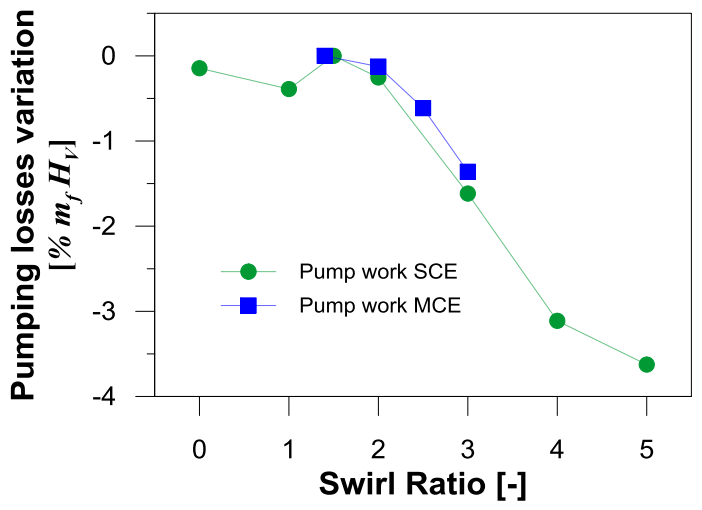

Figure 10. Pumping losses variation considering $S R=1.5$ case as reference Versus swirl ratio sweep for single-cylinder engine and multi-cylinder engine (5 bar BMEP)

So, as expected, figure 10 shows how the highest pumping losses are attained when the highest SR was used. Looking again at figure 7, it can be stated that $\mathrm{SR}=1.5$ presents a GIE much lower than the maximum, which is obtained in $\mathrm{SR}=3$. So, an exploratory test campaign was proposed with the aim of getting the highest engine brake efficiency by combining the lowest pumping losses $(\mathrm{SR}=1.5)$ with the highest GIE ( $\mathrm{SR}=3$ ) conditions. In this sense, the RoHR profile of SR = 3 was used as a pattern to be replicated but using SR $=1.5$ with a different injection strategy. Thus, nominal injection strategy of the $\mathrm{SR}=1.5$ case was varied to fit CA10, CA25, CA50, CA75 and CA90 obtained when engine is operated with a $\mathrm{SR}=3$.

The methodology has been already explained in previous section. In this particular case, the injection pressure was increased from 650 to 800 bar getting as a main result faster and higher peak of RoHR. Injection pressure was increased to get a difference in CA10 and CA25 lower than $0.5^{\circ} \mathrm{CAD}$ between combustion process pattern (SR $=3$ ) and adjusted case $(\mathrm{SR}=1.5)$. Later, $\mathrm{SoE}$ and ET are varied to

Page 8 of 14 achieve a difference lower than $0.5^{\circ} \mathrm{CAD}$ in CA50 and CA75 between combustion process pattern $(\mathrm{SR}=3)$ and adjusted $(\mathrm{SR}=$ 1.5). Finally, a fourth injection (post injection) was added to compensate the worst mixture process during the late combustion when $\mathrm{SR}=1.5$ was used. Total injected mass was maintained constant. Thus, SoE and ET of the post injection were varied to obtain a difference lower than $2^{\circ} \mathrm{CAD}$ in CA90 between combustion process pattern $(\mathrm{SR}=3)$ and adjusted $(\mathrm{SR}=1.5)$.

Thus, figure 11 shows the temporal evolution of RoHR and nondimensional cumulative $\mathrm{HR}$ with $\mathrm{SR}=1.5, \mathrm{SR}=3$ and with $\mathrm{SR}=1.5$ but adjusting different engine settings to get similar RoHR.

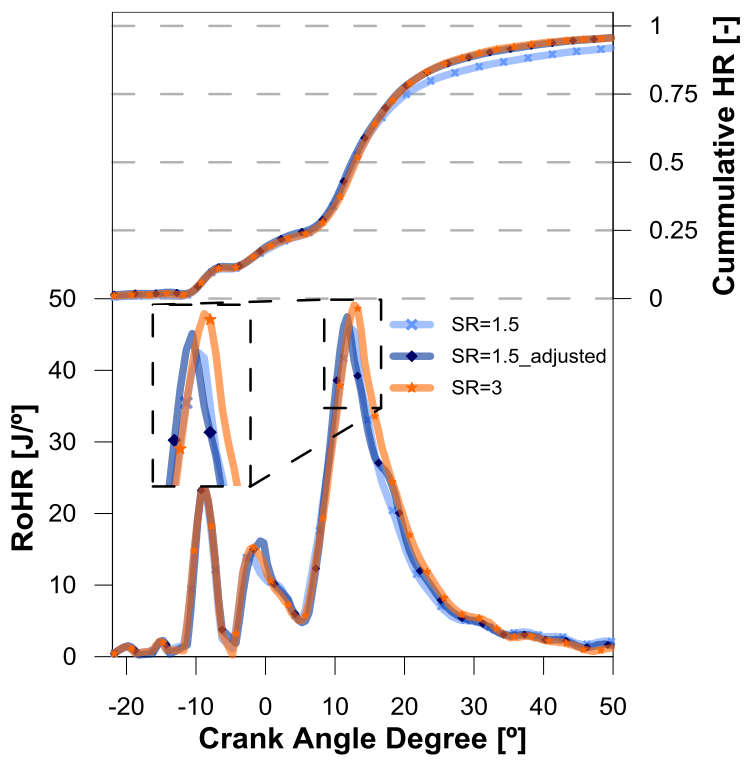

Figure 11. The temporal evolution of the cumulative HR (top) and the RoHR (bottom) for the $\mathrm{SR}=1.5$ and 3 and $\mathrm{SR}=1.5$ adjust to get similar $\mathrm{RoHR}$ at $\mathrm{SR}=$

Thus, to evaluate the accuracy of the RoHR adjustment between SR $=3$ case and $\mathrm{SR}=1.5$ with a new injection strategy, in figure 12 it is presented CA10, CA25, CA50, CA75 and CA90 (tracers to compare onset, development and end part of combustion process). In addition, are also represented combustion duration CA90-CA10 (global combustion duration), CA90-CA50 and CA90-CA75 (last parts of the combustion process).

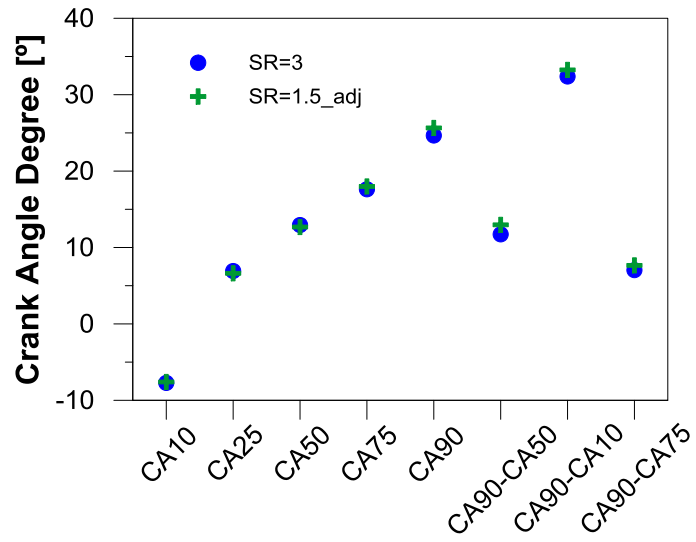

Figure 12. Differences between $\mathrm{SR}=3$ and $\mathrm{SR}=1.5$ adjusted profiles. 
In spite of the experimental effort, it has high complexity to fit completely both RoHR curves. As a consequence, the GIE for SR = 1.5 adjusted differs slightly compared with $S R=3$. From $45.2 \%$ to $45.4 \%$.

Figure 13 it is represented the variation of brake efficiency, the GIE and pumping work for all the SR tested considering as reference case $\mathrm{SR}=1.5$. In addition, the table 7 shows the relatives difference values for all swirl cases compared with the $\mathrm{SR}=1.5$ reference.

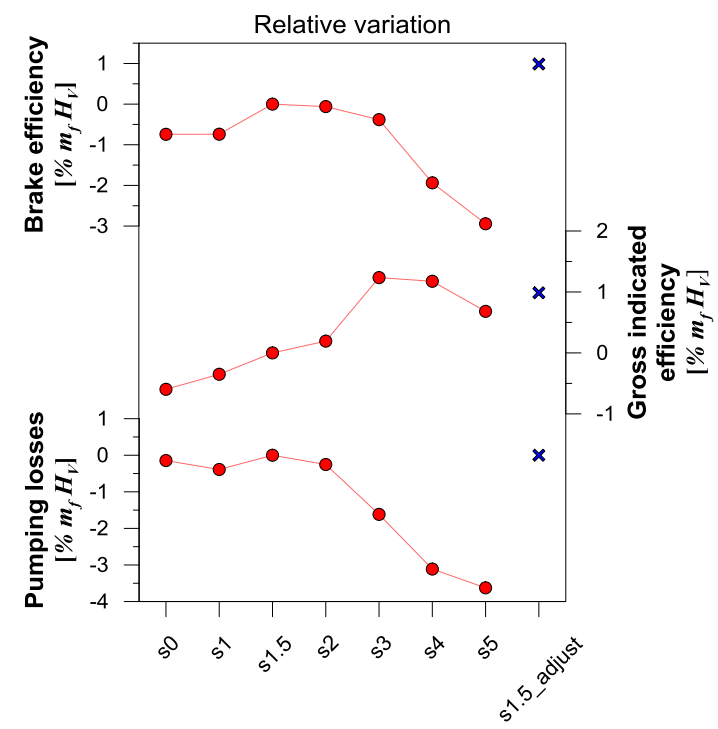

Figure 13. Variation of brake efficiency, the gross indicated efficiency and pumping work for all the SR considering $\mathrm{SR}=1.5$ as references in the SCE.

Table 7. Relative differences of brake efficiency, the gross indicated efficiency and pumping work for the swirl cases respect to $S R=1.5$.

\begin{tabular}{|c|c|c|c|}
\hline $\begin{array}{c}\text { Relative } \\
\text { Differences [\%] }\end{array}$ & $\begin{array}{c}\text { Pumping } \\
\text { losses }\end{array}$ & GIE & $\begin{array}{c}\text { Brake } \\
\text { Efficiency }\end{array}$ \\
\hline $\mathrm{SR}=0-\mathrm{SR}=1.5$ & -0.15 & -0.60 & -0.74 \\
\hline $\mathrm{SR}=1-\mathrm{SR}=1.5$ & -0.39 & -0.35 & -0.74 \\
\hline $\mathrm{SR}=2-\mathrm{SR}=1.5$ & -0.25 & 0.19 & -0.06 \\
\hline $\mathrm{SR}=3-\mathrm{SR}=1.5$ & -1.62 & 1.24 & -0.38 \\
\hline $\mathrm{SR}=4-\mathrm{SR}=1.5$ & -3.11 & 1.18 & -1.94 \\
\hline $\mathrm{SR}=5-\mathrm{SR}=1.5$ & -3.63 & 0.68 & -2.94 \\
\hline $\begin{array}{c}\mathrm{SR}=1.5 \text { adj }- \\
\mathrm{SR}=1.5\end{array}$ & 0.00 & 0.99 & 0.99 \\
\hline
\end{tabular}

So, it is demonstrated that a proper combination of SR and injection strategy can provide benefits in terms of brake efficiency, in this case around $1 \%$. In this sense, the injection strategy proposed (including pulses and injection pressure) conducts to a combustion improvement that leads a better GIE without a penalty in pumping losses. As a result, the best brake Engine efficiency was obtained.

\section{Emissions}

Figure 14 shows NOx, HC, $\mathrm{CO}$ and soot emissions for the $\mathrm{SR}=3$, $\mathrm{SR}=1.5$ and $\mathrm{SR}=1.5$ adjusted. So, considering that combustion process between $\mathrm{SR}=3$ and $\mathrm{SR}=1.5$ adjusting the injection strategy

Page 9 of 14 is quite similar it is also expected to have similar engine out emissions. Figure 15 represents the adiabatic flame temperature and a mixing capability tracer $\left(\mathrm{ACT}^{-1}\right)$, at the same instant $(90 \%$ mass fraction burned). On the first hand, the adiabatic flame temperature was calculated with the assumption of constant pressure at each steps of calculation, adiabatic burning of the stoichiometric fuels/air mixture and considering a conventional chemical equilibrium model, following the scheme proposed by Way [30]. On the other hand, the Apparent Combustion Time (ACT) parameter was used to estimate mixing capability. It is the dwell time between the instant where a certain percentage of the mass of fuel has been injected and the instant where this same percentage is burned [31]. In this study, it was used $\mathrm{ACT}^{-1}$, which is considered as a mixing capability tracer.

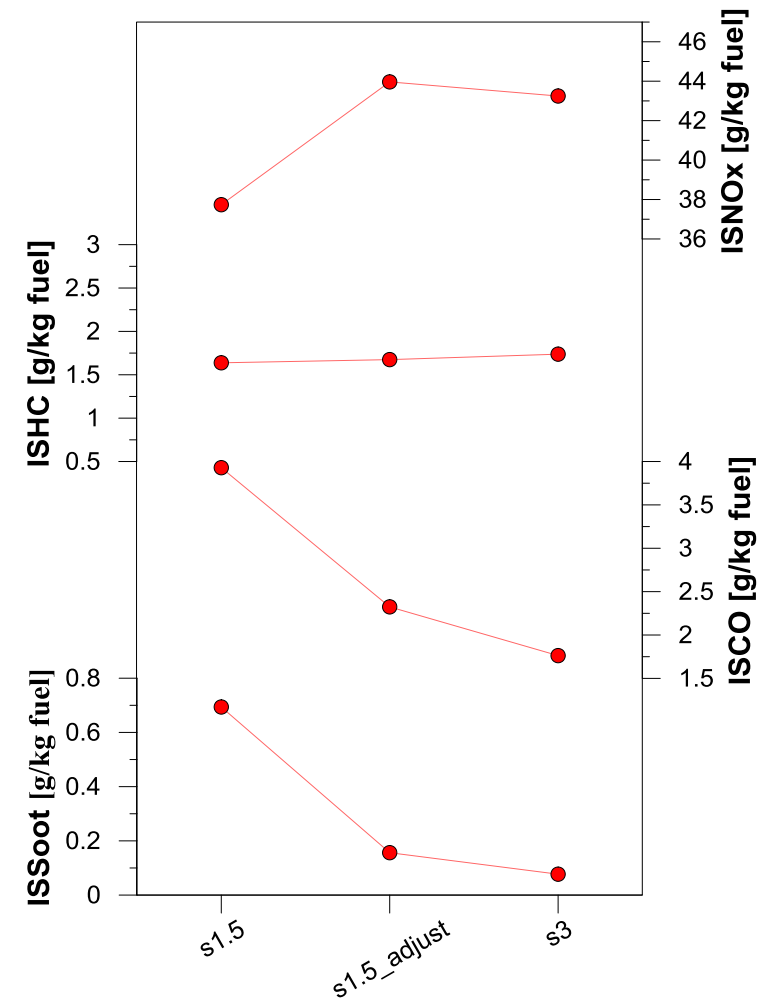

Figure 14. NOx, HC, $\mathrm{CO}$ and soot emissions for $\mathrm{SR}=3, \mathrm{SR}=1.5$ and $\mathrm{SR}=$ 1.5 adjusted.

According to figure 15 it was possible to state that $\mathrm{SR}=3$ (due higher air flow motion) and $\mathrm{SR}=1.5$ adjusted (due to a new injection strategy) promote faster mixing process as well as higher oxidation process, which is reflected in higher flame temperatures and lower apparent combustion time. As a consequence, soot and $\mathrm{CO}$ oxidation was enhanced and therefore final measured values were lower. By contrast, NOx emissions were higher. $\mathrm{HC}$ were maintained constant independent of the different swirl ratios and injection strategies tested. 


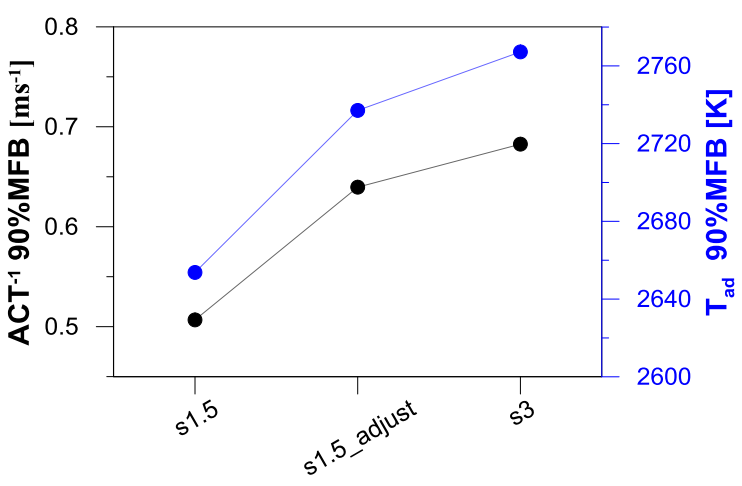

Figure 15. Adiabatic flame temperature and mixing capability tracer $\left(\mathrm{ACT}^{-1}\right)$ at the same instant (90\% mass fraction burned) for $\mathrm{SR}=3, \mathrm{SR}=1.5$ and $\mathrm{SR}=$ 1.5 adjusted.

\section{High load case: 20 bar BMEP}

\section{Engine efficiency study}

As in the low load case, as a first approach, a complete swirl sweep was performed at 2000rpm at 20bar BMEP controlling the CA50. Figure 16 presents the GIE as a function of different swirl ratios. In the figure are depicted results from SCE and MCE. These last, also obtained in a previous work [28]. Comparing both versions of similar engine it can be said that the maximum benefit is obtained at different SR levels. SR $=1.4$ for the MCE and SR $=3$ for the SCE. As explained previously, this fact is mainly due to differences in the valve ports. The GIE benefit for the case SCE is around $2.1 \%$ between the $\mathrm{SR}=0$ and $\mathrm{SR}=3$.

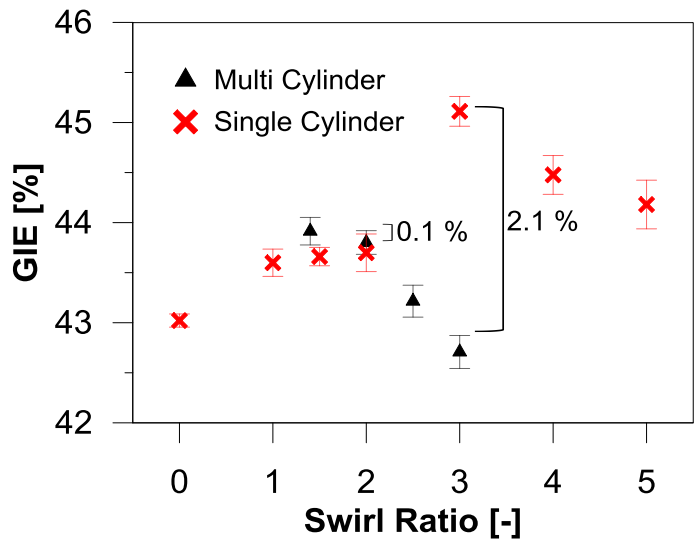

Figure 16. Gross Indicated Efficiency variation Vs swirl ratio sweep considering $\mathrm{SR}=1.5$ as reference case and splitting the RoHR and heat transfer effects (20 bar BMEP).

Figure 17 presents the temporal evolution of the RoHR and the cumulative HR for the 7 different swirl ratios tested. Thus, it can be stated that during the pilot injections combustion there is no significant differences between different swirl ratios proposed. By contrast, during the main combustion, it can be said that the first combustion stage is enhanced when the SR is increased (RoHR slopes are sharper with higher SR, considering CA25 as tracer). On the other side, considering the peaks of the curves, it seems that from $\mathrm{SR}=0$ up to $\mathrm{SR}=4$, the maximum peak of RoHR is increased when the $\mathrm{SR}$ is increased. Nonetheless, with $\mathrm{SR}=5$ this effect is completely lost and peak of RoHR decreases, even lower than the level of $\mathrm{SR}=0$. This behavior can be explained by an excessive sprays interaction [29] and/or a displacement of the combustion process towards the squish region which implies a worsening in combustion [29].

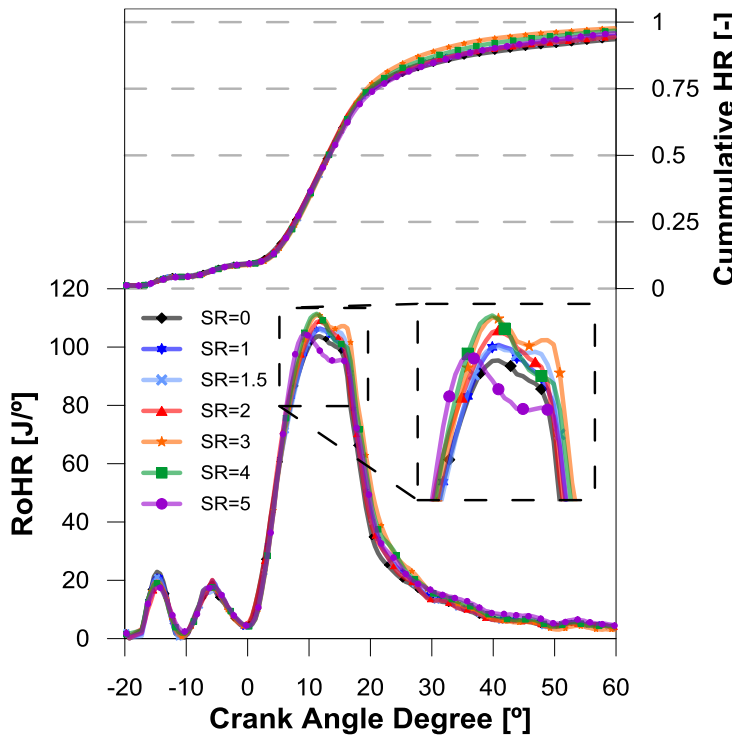

Figure 17. The temporal evolution of the cumulative AHR (top) and the RoHR (bottom) for the different swirl ratios tested.

As with the low load case, a dedicated analysis with a OD code is made to evaluate the GIE enhancement from $\mathrm{SR}=0$ up to $\mathrm{SR}=3$ and its following worsening. So, an adiabatic combustion is simulated to isolate combustion and heat transfer effects. Thus, figure 18 shows the improvement and/or worsening in the indicated efficiency versus the different SR using the lowest SR case values as reference. Thus, GIE is considered as the result of adding combustion (increases GIE) and heat transfer (decreases GIE) effects.

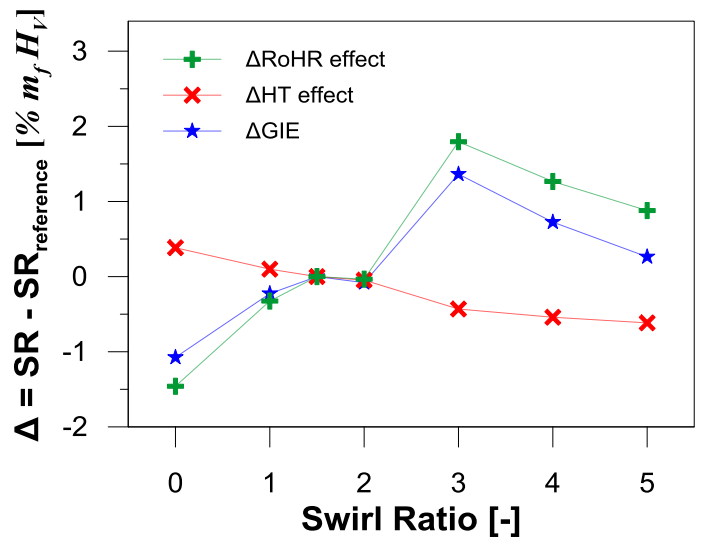

Figure 18. Effect of RoHR and heat transfer in Gross Indicated Efficiency at swirl ratio sweep.

Once the SR impact on GIE is evaluated at high load, it is needed to study the pumping work. Following similar work schematic than in low load case, 1D modelling work was developed. Thus, adjusting the model with MCE, pumping losses for the SCE are obtained for each one of the different SR proposed.

Page 10 of 14 


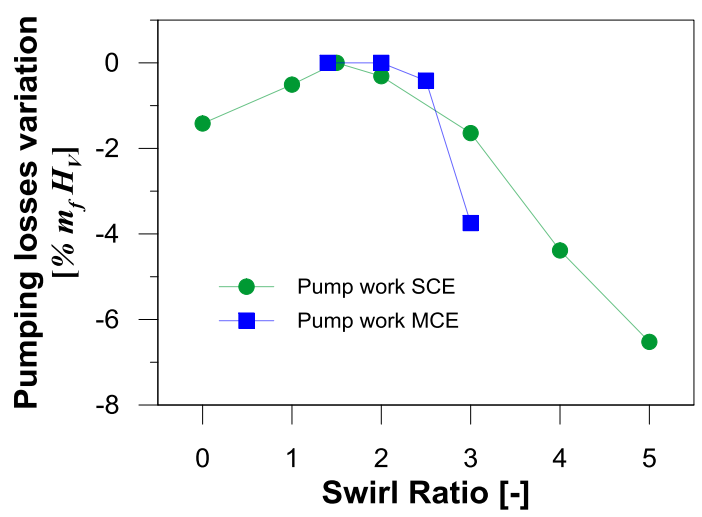

Figure 19. Pumping losses variation considering $\mathrm{SR}=1.5$ case as reference versus swirl ratio sweep for single-cylinder engine and multi-cylinder engine. (20 bar BMEP).

So, case of $\mathrm{SR}=1.5$ is providing the lowest pumping work. In this sense, in figure 19 it is shown the pumping work variation compared with SR $=1.5$ for the different SR tested. It is stated the highest pumping losses are found in the highest SR.

Following the same methodology, a dedicated experimental work is performed to achieve the highest engine efficiency by combining the highest GIE with the lowest pumping losses. For that purpose, the injection strategy of the $\mathrm{SR}=1.5$ (lowest pumping work) was modified to obtain similar RoHR than in the $\mathrm{SR}=3$ (the highest GIE). Thus, the injection pressure has been increased from 1250 to 1350 bar as well as SoE's and ET's variations have been made including a post injection. As in previous case, the criteria to increase injection pressure is to get lower than $0.5^{\circ} \mathrm{CAD}$ difference between nominal and adjusted CA10 and CA25.

Figure 20 shows a comparison of CA10, CA25, CA50, CA75 and CA90 obtained from the RoHR profiles when $\mathrm{SR}=3$ case and $\mathrm{SR}=$ 1.5 with a new injection strategy case are used.

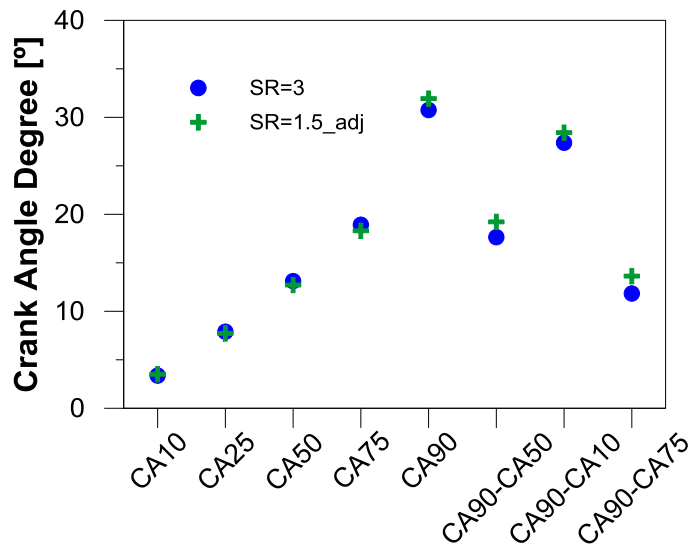

Figure 20. Differences between $\mathrm{SR}=3$ and $\mathrm{SR}=1.5$ adjusted profiles.

Thus, although a significant experimental work was made and different injection strategies were tested, there were some differences in the last part of the combustion process that were not possible to overcome. In this sense, there are some discrepancies between GIE of $\mathrm{SR}=3,45.1 \%$ and GIE of $\mathrm{SR}=1.5$ adjusted, $44.5 \%$

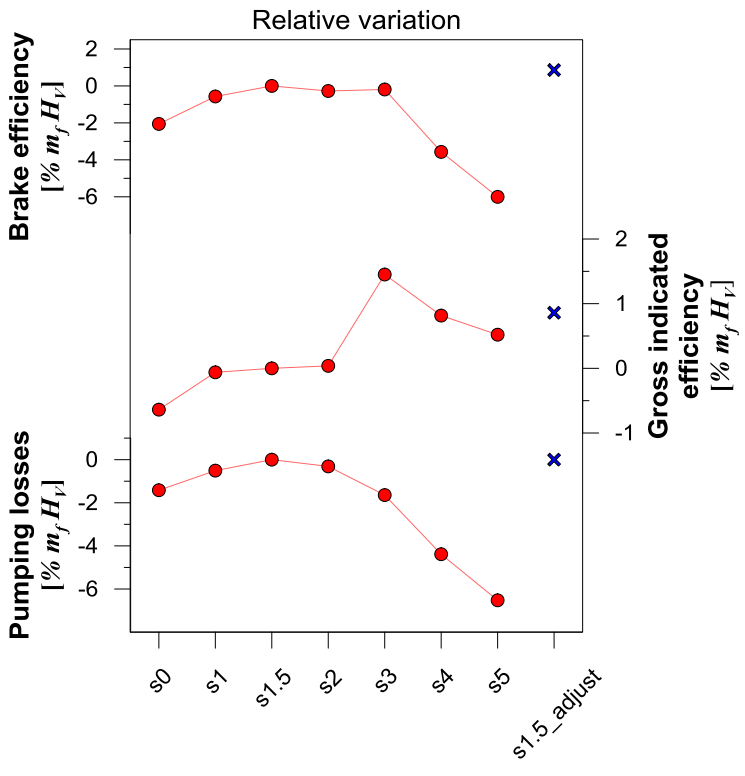

Figure 21. Brake efficiency, the gross indicated efficiency and pumping work for all the SR together with the optimized case in the SCE.

Figure 21 shows variation of brake efficiency, the GIE and pumping work for all the SR tested considering as reference case $\mathrm{SR}=1.5$. So, by combining SR and injection strategy the brake efficiency at high load can be improved $0.8 \%$. In addition, as in the low load test, the table 8 shows the relatives difference values for all swirl cases compared with the $\mathrm{SR}=1.5$ reference.

Table 8. Relative differences of brake efficiency, the gross indicated efficiency and pumping work for the swirl cases respect to $S R=1.5$.

\begin{tabular}{|c|c|c|c|}
\hline $\begin{array}{c}\text { Relative } \\
\text { Differences [\%] }\end{array}$ & $\begin{array}{c}\text { Pumping } \\
\text { losses }\end{array}$ & GIE & $\begin{array}{c}\text { Brake } \\
\text { Effiency }\end{array}$ \\
\hline $\mathrm{SR}=0-\mathrm{SR}=1.5$ & -1.42 & -0.64 & -2.06 \\
\hline $\mathrm{SR}=1-\mathrm{SR}=1.5$ & -0.51 & -0.06 & -0.57 \\
\hline $\mathrm{SR}=2-\mathrm{SR}=1.5$ & -0.31 & 0.04 & -0.27 \\
\hline $\mathrm{SR}=3-\mathrm{SR}=1.5$ & -1.64 & 1.45 & -0.19 \\
\hline $\mathrm{SR}=4-\mathrm{SR}=1.5$ & -4.39 & 0.82 & -3.57 \\
\hline $\mathrm{SR}=5-\mathrm{SR}=1.5$ & -6.52 & 0.52 & -6.00 \\
\hline $\begin{array}{c}\mathrm{SR}=1.5 \_ \text {adj }- \\
\mathrm{SR}=1.5\end{array}$ & 0.00 & 0.86 & 0.86 \\
\hline
\end{tabular}


Emissions

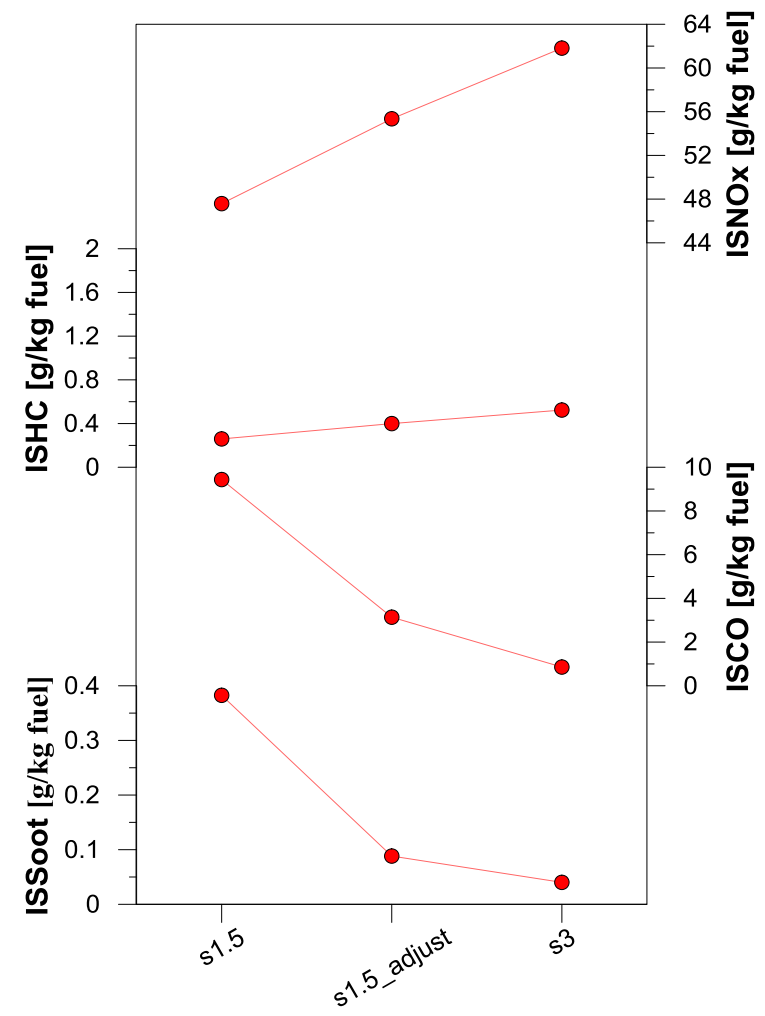

Figure 22. NOx, HC, $\mathrm{CO}$ and soot emissions for the $\mathrm{SR}=3, \mathrm{SR}=1.5$ and $\mathrm{SR}$ $=1.5$ adjusted.

Figure 22 shows NOx, HC, $\mathrm{CO}$ and soot emissions for the $\mathrm{SR}=3$, $\mathrm{SR}=1.5$ and $\mathrm{SR}=1.5$ adjusted. As it is expected, similar engine out emissions were obtained between $\mathrm{SR}=3$ and $\mathrm{SR}=1.5$ adjusted considering that combustion process was quite similar. Low soot levels attained with high swirl ratios were also obtained with lower swirl levels and proper injection strategy. In this sense, figure 23 demonstrates that hypothesis. As in the low load condition, $\mathrm{SR}=3$ and $\mathrm{SR}=1.5$ adjusted enhance the mixing and oxidation process which is indicated by higher flame temperature and lower apparent combustion time, resulting in lower values of $\mathrm{CO}$ and soot. By contrast, NOx emissions were higher. In addition, it is interesting to highlight that with the injection strategy proposed for $\mathrm{SR}=1.5, \mathrm{HC}$ emissions remain almost constant compared with $\mathrm{SR}=3$.

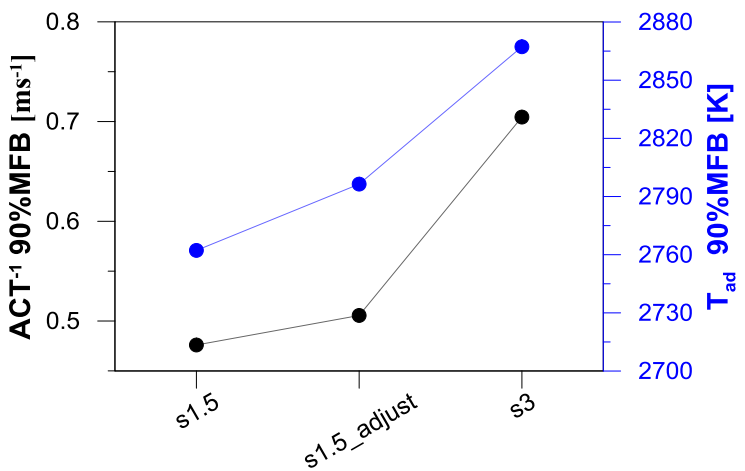

Figure 23. Adiabatic flame temperature and mixing capability tracer $\left(\mathrm{ACT}^{-1}\right)$ at the same instant (90\% mass fraction burned) for $\mathrm{SR}=3, \mathrm{SR}=1.5$ and $\mathrm{SR}=$ 1.5 adjusted.

\section{Conclusions}

Modelling calculations and experiments have been performed in a single-cylinder diesel engine to study different strategies to maximize the engine efficiency using different injection strategies and swirl ratios. In this sense, a particular experimental methodology has been developed to get the maximum engine efficiency. Thus, the most relevant findings were:

- $\quad$ Specific 0D calculations have been made to split and clarify the experimental found effects of swirl variation on indicated efficiency. These, results demonstrate how to increase the swirl ratio always increases the heat transfer as well as produces an improvement on combustion process up to a maximum. After this maximum, an increase in swirl level only provides drawbacks since it also deteriorates the combustion development due to excessive spray interaction and/or a displacement of the combustion process towards the squish region.

- $\quad$ 1D modelling calculations have been performed to obtain pumping work when swirl ratio is varied. Results show how an increase in swirl ratio implies higher pumping losses. Moreover, quantifying these losses, it seems that variations on pumping work due to swirl ratio variations have stronger effect than variations on indicated efficiency.

- The injection strategies have an important influence on efficiency. The efficiency and emission impact of swirl levels was improved with suitable injection pattern (increase of injection pressure and add the post injection event mainly) due to the spray-driven mixing energy produces an increase in the in-cylinder air movement and thus, the mixing/combustion process improves essentially.

- With a suitable injection strategy combined with injection pressure, it is possible to get similar indicated efficiency independently on the swirl ratio used. Thus, selecting the swirl ratio level which provides the lowest pumping work as well as the injection strategy that maximizes the indicated efficiency, it is possible to maximize the brake 
engine efficiency only by using the existent engine hardware.

- According to the emission results obtained, the expected soot-NOx trade-off was found. So, considering that combustion process between $\mathrm{SR}=3$ and $\mathrm{SR}=1.5$ adjusting the injection strategy was quite similar, it was also expected to have similar engine out emissions. Thus, the positive impact of high swirl on $\mathrm{CO}$ and soot reduction can be also attained with lower swirl ratio and a proper injection strategy. On the contrary, NOx emissions increased appreciably when the mixing process is enhanced $(\mathrm{SR}=3$ and $\mathrm{SR}=1.5$ adjusted). $\mathrm{HC}$ emissions were maintained constant independent of the different swirl ratios and injection strategies tested.

\section{References}

1. Knecht W. "Diesel engine development in view of reduced emission stardards". Energy 33 (2) (2008) 264271.doi:10.1016/j.energy.2007.10.003

2. Caresana, F., Bilancia, M., Bartolini C.M., "Numerical method for assessing the potential of smart engine thermal management: Application to a medium-upper segment passenger car", Appl. Therm. Eng. 31(16), 3559-3568, 2011, doi:10.1016/j.applthermaleng.2011.07.017.

3. Chalgren, R. and Allen, D., "Light Duty Diesel Advanced Thermal Management," SAE Technical Paper 2005-012020, 2005, doi: 10.4271/2005-01-2020.

4. Dimopoulos, P., Bacha, C., Soltica, P., Boulouchos, K., "Hydrogen-natural gas blends fuelling passenger car engines: Combustion, emissions and well-to-wheels assessment", Int. J. Hydrogen Energ. 33(23), 72247236,2008, doi:10.1016/j.ijhydene.2008.07.012.

5. Osada, H., Uchida, N., Shimada, K., and Aoyagi, Y., "Reexamination of Multiple Fuel Injections for Improving the Thermal Efficiency of a Heavy-Duty Diesel Engine," SAE Technical Paper 2013-01-0909, 2013, doi:10.4271/2013-01-0909.

6. Benajes, J., Martin, J., Garcia, A., Villalta, D.,Warey A. et al., "An Investigation of Radiation Heat Transfer in a Light-Duty Diesel Engine," SAE Int. J. Engines 8(5):2015, doi:10.4271/2015-24-2443.

7. Lopez, J., Martin, J., Garcia, A., Villalta, D. Warey A. et al., "Characterization of In-Cylinder Soot Oxidation Using Two-Color Pyrometry in a Production Light-Duty Diesel Engine," SAE Technical Paper 2016-01-0735, 2016, doi:10.4271/2016-01-0735.

8. Benajes, J., Martin, J., Garcia, A., Villalta, D.,Warey A. "In-cylinder soot radiation heat tranfer in direct-injection diésel engines". Energy Conversion and Management 106 (2015) 414-427.

9. Serrano, J., Olmeda, P., Tiseira, A., García-Cuevas, L. et al., "Importance of Mechanical Losses Modeling in the Performance Prediction of Radial Turbochargers under Pulsating Flow Conditions," SAE Int. J. Engines 6(2):729738, 2013, doi:10.4271/2013-01-0577.

10. Benajes, J. et al., "Analysis of the combustion process, pollutant emissions and efficiency of an innovative 2-stroke HSDI engine designed for automotive applications", Appl. Therm. Eng., 58(1-2), 181-193, doi:10.1016/j.applthermaleng.2013.03.050.

11. J. Benajes, S. Molina, A. García, J. Monsalve-Serrano, "Effects of low reactivity fuel characteristics and blending ratio on low load RCCI (reactivity controlled compression ignition) performance and emissions in a heavy-duty diesel engine." Energy, Volume 90, October 2015, Pages 12611271.

12. J. Benajes, A. García, José M. Pastor, J. Monsalve-Serrano, "Effects of piston bowl geometry on Reactivity Controlled Compression Ignition heat transfer and combustion losses at different engine loads." Energy, Volume 98, 1 March 2016, Pages 64-77.

13. J. Benajes, A. García, J. Monsalve-Serrano, I. Balloul, G. Pradel, "An assessment of the dual-mode reactivity controlled compression ignition/conventional diesel combustion capabilities in a EURO VI medium-duty diesel engine fueled with an intermediate ethanol-gasoline blend and biodiesel." Energy Conversion and Management, Volume 123, 1 September 2016, Pages 381-391.

14. Miles, P., "The Influence of Swirl on HSDI Diesel Combustion at Moderate Speed and Load," SAE Technical Paper 2000-01-1829, 2000, doi:10.4271/2000-01-1829

15. J. Heywood, "Internal Combustion Engines Fundamentals," McGraw-Hill, New York, 1988.

16. Dembinski H., Angstrom H. "Swirl and Injection Impact on After-Oxidation in Diesel Combustion, Examined with Simultaneous Combustion Image Velocimetry and Two Colour Optical Method". SAE Technical Paper 2013-010913, 2013, doi:10.4271/2013-01-0913.

17. Arrègle J., Pastor J.V., López J.J., García A. "Insights on postinjection-associated soot emissions in direct injection diesel engines". Combustion and flame 154 (2008), 448461. doi: 10.1016/j.combustflame.2008.04.021.

18. J. ichi Kawashima, "Research on a variable swirl 551 intake port for high-speed 4-valve (DI) diesel engine," (JSAE) Review $20 \quad$ (3) (1999) $421 \quad$ - 552424. doi:http://dx.doi.org/10.1016/S0389-4304(99)00025-9.

19. Payri F, Lujan JM, Martín J, Abbad A. "Digital signal processing of in-cylinder pressure for combustion diagnosis of internal combustion engines." Mech Syst Signal Process 2010;24:1767-84.

20. DRIVVEN Stand Alone Direct Injector Driver System User's Manual October 2010. Drivven, INC. 12001 Network Blvd, 110. San Antonio, Texas 78249. Web: www.drivven.com<http://www.drivven.com>

21. Payri, F., Olmeda, P., Martin, J., and Carreño, R., "A New Tool to Perform Global Energy Balances in DI Diesel Engines," SAE Int. J. Engines 7(1):43-59, 2014, doi:10.4271/2014-01-0665.

22. Payri F., Olmeda P., Martín J., García, Antonio. “A complete OD thermodynamic predictive model for direct injection diesel engines", Applied Energy (88) (2011) 4632-4641. doi:10.1016/j.apenergy.2011.06.005.

23. Payri, F., Galindo, J., Martín, J., and Arnau, F., "A Simple Model for Predicting the Trapped Mass in a DI Diesel Engine," SAE Technical Paper 2007-01-0494, 2007, doi:10.4271/2007-01-0494.

24. Lapuerta M, Armas O, Hernández JJ. "Diagnosis of DI Diesel combustion from in- cylinder pressure signal by estimation of mean thermodynamic properties of the gas". Appl Thermal Eng 1999;19(5):513-29. http://dx.doi.org/10.1016/S1359-4311(98)00075-1.

25. Payri F, Molina S, Martín J, Armas O. "Influence of measurement errors and estimated parameters on combustion diagnosis". Appl Thermal Eng 2006; 26(23):226-3, http://dx.doi.o10.1016/j.applthermaleng.2005.05.006. 
26. Payri, F., Margot, X., Gil, A., and Martin, J., "Computational Study of Heat Transfer to the Walls of a DI Diesel Engine," SAE Technical Paper 2005-01-0210, 2005, doi:10.4271/2005-01-0210.

27. Benajes, J., Olmeda, P., Martín, J. and Carreño, R., “A new methodology for uncertainties characterization in combustion diagnosis and thermodynamic modelling", Applied Thermal Engineering 71:389-399, 2014, doi:10.1016/j.applthermaleng.2014.07.010.

28. Olmeda, P., Martin, J., Garcia, A., Blanco, D. et al., "Evaluation of EGR Effect on the Global Energy Balance of a High Speed DI Diesel Engine," SAE Technical Paper 2016-01-0646, 2016, doi:10.4271/2016-01-0646.

29. De la Morena J., Vassallo A. Peterson R.C., Gopalakrishan V., Gao J. "Influence of Swirl Ratio on Combustion System Performance of a 0.41 Single-Cylinder Diesel Engine". THIESEL 2014 Conference on Thermo- and Fluid Dynamic Processes in Direct Injection Engines.

30. Way RJB. "Methods for determination of composition and thermodynamic properties of combustion products for internal combustion engine calculations". P I Mech Eng 1976;190:686e97.

31. López, J., Martin, J., Garcia, A., Villalta, D.,Warey A. "Implementation of two color method to investigate late cycle soot oxidation process in a CI engine under low load conditions". Applied Thermal Engineering 113 (2017) 878-890.

\section{Contact Information}

Dr. Antonio García

CMT-Motores Térmicos, Universitat Politècnica de València

Camino de Vera s/n, 46022 Valencia (Spain)

e-mail: angarma8@ mot.upv.es

web: www.cmt.upv.es

\section{Acknowledgments}

The support of GM Global R\&D and the Spanish Ministry of Economy and Competitiveness (TRA2014-58870-R,) is greatly acknowledged.

\section{Definitions/Abbreviations}

$\begin{array}{ll}\text { BMEP } & \begin{array}{l}\text { Brake Mean Effective } \\ \text { Pressure }\end{array} \\ \text { CA50 } & \begin{array}{l}\text { Crank angle degree in which } \\ 50 \% \text { of the total fuel quantity } \\ \text { is already burned }\end{array} \\ \text { CAD } & \text { Crank Angle Degree } \\ \text { CO2 } & \text { Carbon Dioxide } \\ \text { DI } & \text { Direct Injection } \\ \text { EGR } & \text { Exhaust Gas Recirculation } \\ \text { ET } & \text { Energizing Time }\end{array}$

Page 14 of 14

\begin{tabular}{ll} 
FSN & Filter Smoke Number \\
GHG & Greenhouse Gas \\
GIE & Gross Indicated Efficiency \\
HR & Heat Release \\
HT & Heat Transfer \\
ICE & Internal Combustion Engine \\
IMEP & Indicated Mean Effective \\
IVC & Pressure \\
MCE & Intake Valve Closing \\
NOx & Multi-Cylinder Engine \\
Pexh & Nitrogen Oxide \\
Pin & Exhaust Pressure \\
RoHR & Start Of Energizing \\
SCE & Intake Pressure \\
& Rate of Heat Release \\
\hline
\end{tabular}

